Original Article

\title{
STABILITY INDICATING HPTLC METHOD FOR DETERMINATION OF CLEVIDIPINE BUTYRATE IN SYNTHETIC MIXTURE
}

\author{
CHARU P. PANDYA, SADHANA J. RAJPUT*
}

Quality Assurance Laboratory, Center of Relevance and Excellence in Novel Drug Delivery System, Faculty of Pharmacy, Shri G. H. Patel Pharmacy Building, The Maharaja Sayajirao University of Baroda, Fatehgunj, Vadodara 390002, Gujarat, India

Email: sjrajput@gmail.com

Received: 21 Mar 2018 Revised and Accepted: 15 May 2018

ABSTRACT

Objective: To develop and validate stability indicating HPTLC method for determination of clevidipine butyrate in synthetic mixture.

Methods: The present study deals with development and validation of stability indicating HPTLC method for estimation of clevidipine butryate. Chromatographic separation was performed on aluminum plate pre coated with Silica Gel 60 F254 using toluene: ethyl acetate (8:2) as mobile phase. TLC scanner was set at wavelength of $370 \mathrm{~nm}$.

Results: Retention factor $\mathrm{R}_{\mathrm{f}}$ of clevidipine was found to be 0.49 . The method was validated as per ICH guidelines. Calibration curve was in the range of $1000-6000 \mathrm{ng} / \mathrm{band}$. The correlation coefficient was found to be 0.999 . The precision expressed by RSD was less than $2 \%$. The accuracy of method was confirmed by recovery studies using standard addition method and recovery was found to be $99.03-99.57 \%$. The drug was subjected to ICH prescribed hydrolytic, oxidative, photolytic and thermal stress conditions. Clevidipine and its degradation products were well resolved under experimental conditions. The method was validated according to ICH guidelines. The drug showed significant degradation in alkaline and acidic condition and slight degradation in oxidative condition. The drug was stable in thermal condition.

Conclusion: A new, Simple, Accurate, Precise, Sensitive and economic stability indicating HPTLC method has been developed and validated for the determination of clevidipine and can be employed for stability indicating analysis.

Keywords: Clevidipine butryate, Stability indicating HPTLC method, ICH Guidelines

(C) 2018 The Authors. Published by Innovare Academic Sciences Pvt Ltd. This is an open access article under the CC BY license (http://creativecommons.org/licenses/by/4.0/) DOI: http://dx.doi.org/10.22159/ijpps.2018v10i6.26110

\section{INTRODUCTION}

Clevidipine butyrate (CLEVI) is dihydropyridine L-type calcium channel blocker that is selective for vascular smooth muscle [1]. It is indicated for reduction of blood pressure when oral therapy is not possible [2]. It is available as lipid emulsion for intravenous infusion and is approved in US. It is marketed as Cleviprex by The Medicines Company [3]. It is effective in the treatment of both preoperative and post operative hypertension in adult cardiac surgery patients with rapid onset and short duration of action. Chemical name of CLEVI is methyl 5-\{[(butanoyloxy) methoxy] carbonyl\}-4-(2,3dichlorophenyl)-2,6-dimethyl-1,4-dihydropyridine-3-carboxylate. Literature survey reveals determination of CLEVI and its metabolite by HPLC method [4]. LC-MS/MS methods are reported for determination of CLEVI [5-7]. Various methods are reported for determination of related substances of clevidipine butyrate by HPLC method [9-11].

Force degradation studies have an important role in the development of pharmaceuticals. ICH guidelines requires that stability of samples should be analysed by stability indicating assay method which is to be developed by stress testing in conditions like hydrolytic, oxidative, thermal and photolytic and validated. To the best of our knowledge stability indicating method of clevidipine by HPTLC method has not been reported. HPTLC method has several advantages over HPLC methods. It is economic, samples can be analysed with shorter run time, low mobile phase consumption per sample. It facilitates automatic sample application and scanning to the plate, can handle large no. of samples at a time and is sensitive.

The objective of the present study was to develop simple, economical, specific, precise, accurate and reproducible HPTLC method development for the determination of clevidipine butyrate in bulk and synthetic mixture. The developed analytical method was validated for linearity, accuracy, precision, sensitivity and robustness as per ICH guidelines.

\section{MATERIALS AND METHODS}

\section{Chemicals and Reagents}

Clevidipine butyrate (CLEVI) was purchased from Angene Chemical Ltd, China. Toluene, methanol, ethyl acetate of HPLC grade was purchased from SD Fine Chemical Ltd., Mumbai Pvt. Ltd.

\section{Instrumentation and chromatographic conditions}

Linomat 5 sample applicator (Camag, Switzeland), twin trough chamber (20 X $10 \mathrm{~cm}$; Camag, Switzerland), TLC scanner IV(Camag, Switzerland), winCATS version 1.4.6 software (Camag, Switzerland), Hamilton microlitre syringe (Linomat syringe 659.0014, Hamilton Bonaduz Schweiz, Camag, Switzerland), UV chamber (Camag, Switzerland), precoated silica gel 60F254 aluminium plates (20X 20 cm,100 mm thickness; E. Merck, Darmstadt, Germany) were used in the study.

\section{Optimized chromatographic conditions}

Standard solutions and sample solutions were applied to the HPTLC plates from the bottom and $10 \mathrm{~mm}$ from the side edges in the form of bands with the band length of $6 \mathrm{~mm}$ on the pre-coated silica gel aluminium plate 60 F $254(20 \times 20 \mathrm{~cm}), 100 \mu \mathrm{m}$ thickness, using Camag Linomat $\mathrm{V}$ sample applicator. The mobile phase was toluene: ethyl acetate (8:2). Mobile phase components were mixed prior to use and the development chamber was left to saturate with mobile phase vapor for $20 \mathrm{~min}$ before each run. Ascending method development was carried out to a migration distance of $80 \mathrm{~mm}$. TLC plates were dried in a current of air with air dryer. Scanning was performed at wavelength of $370 \mathrm{~nm}$ reflectance absorbance mode, slit dimension 6 X $0.3 \mathrm{~mm}$, micro), scanning speed $20 \mathrm{~mm} / \mathrm{sec}$, data resolution $100 \mu \mathrm{m} / \mathrm{step}$, optical filter second order, filter factor (Savitsky Golay 7). The source of radiation was deuterium lamp emitting a continuous UV spectrum of 200 to $400 \mathrm{~nm}$. Data was integrated with WINCATS software. 


\section{Preparation of solutions}

\section{Standard solutions}

Standard stock solutions were prepared by dissolving $10 \mathrm{mg}$ of CLEVI in methanol in $10 \mathrm{ml}$ of volumetric flask. Different volumes of stock solution $(1,2,3,4,5$ and $6 \mu \mathrm{l})$ solution were applied as band to the HPTLC plate to make concentration in the range of 1000 $6000 \mathrm{ng} /$ band.

\section{Sample solution assay}

CLEVI marketed formulation could not be imported and it was prepared as laboratory synthetic mixture as per the given formula [13] in table 1.

\section{Forced degradation study}

Stock solution of CLEVI was prepared by dissolving $250 \mathrm{mg}$ of CLEVI in $25 \mathrm{ml}$ of methanol. This stock was used for degradation studies.

Table 1: Composition of CLEVI synthetic mixture

\begin{tabular}{ll}
\hline Composition & \%w/v \\
\hline Clevidipine & 0.05 \\
Soyabean oil & 20 \\
Glycerin & 2.25 \\
Disodium Edetate & 0.005 \\
Sodium citrate & 0.1 \\
Egg yolk phospholipid & 1.2 \\
Water for injection & upto $100 \%$ \\
\hline
\end{tabular}

\section{Acid degradation}

$2.5 \mathrm{ml}$ of stock solution of CLEVI was taken in $25 \mathrm{ml}$ of volumetric flask, $1 \mathrm{ml}$ of $1 \mathrm{~N} \mathrm{HCl}$ was added and solution was heated in a water bath at $60{ }^{\circ} \mathrm{C}$ for 1 hour. The solution was cooled and neutralized with $1 \mathrm{~N} \mathrm{NaOH}$. Volume was made upto $25 \mathrm{ml}$ with methanol to make concentration of $1 \mathrm{mg} / \mathrm{ml}$. The solution was filtered through $0.45 \mu$ Nylon 6,6 membrane syringe filter. From this solution $5 \mu \mathrm{l}$ (5000 ng/band) was applied to HPTLC plate and development was carried out under optimized chromatographic conditions.

\section{Base degradation}

$2.5 \mathrm{ml}$ of stock solution of CLEVI was taken in $25 \mathrm{ml}$ of volumetric flask, $1 \mathrm{ml}$ of $0.01 \mathrm{~N} \mathrm{NaOH}$ was added and solution was heated in a water bath at $60{ }^{\circ} \mathrm{C}$ for 1 hour. The solution was cooled and neutralized with $0.01 \mathrm{~N} \mathrm{HCl}$. Volume was made upto $25 \mathrm{ml}$ with methanol to make concentration of $1 \mathrm{mg} / \mathrm{ml}$. The solution was filtered through $0.45 \mu$ Nylon 6,6 membrane syringe filter. From this solution $5 \mu \mathrm{l}$ (5000 ng/band) was applied to HPTLC plate and development was carried out under optimized chromatographic conditions.

\section{Oxidative degradation}

$2.5 \mathrm{ml}$ of stock solution of CLEVI was taken in $25 \mathrm{ml}$ of volumetric flask, $1 \mathrm{ml}$ of $3 \%$ hydroegen peroxide was added. The solution was kept at room temperature for $1 \mathrm{hr}$. The solution was made upto volume with methanol. The solution was filtered through $0.45 \mu$ Nylon 6,6 membrane syringe filter. From this solution $5 \mu \mathrm{l}(5000$ ng/band) was applied to HPTLC plate and development was carried out under optimized chromatographic conditions.

\section{Thermal conditions}

$25 \mathrm{mg}$ of CLEVI was placed in oven at 80 for $8 \mathrm{~d}$ under dry heat conditions in the dark and then cooled to room temperature. Volume was made with methanol to get the concentration of $1 \mathrm{mg} / \mathrm{ml}$. From this solution $5 \mu \mathrm{l}$ ( $5000 \mathrm{ng} / \mathrm{band})$ was applied to HPTLC plate and development was carried out under optimized chromatographic conditions.

\section{Photolytic degradation}

For the photochemical study, CLEVI equivalent to $25 \mathrm{mg}$ was spread in $1 \mathrm{~mm}$ thickness on a petridish and exposed to 5383 Lux and 144 $\mathrm{UV} / \mathrm{cm}^{2}$ for $11 \mathrm{~d}$ and volume was made upto $25 \mathrm{ml}$ with methanol to make concentration of $1 \mathrm{mg} / \mathrm{ml}$. From this solution $5 \mu \mathrm{l}(5000$ $\mathrm{ng}$ /band) was applied to HPTLC plate and development was carried out under optimized chromatographic conditions.

\section{Validation}

The method was validated as per ICH guidelines.

\section{Linearity}

The appropriate volume of standard API was spotted on a TLC plate to cover the range of 1000-6000 ng/band. The standard calibration graph of peak area versus concentration was plotted. Linearity was repeated thrice. The linearity of method was evaluated by linear regression analysis using the least square method. The slope and intercept were calculated.

\section{Accuracy (Recovery Study)}

Recovery studies were performed by standard addition method where known amount of standard samples were spiked to analyzed dosage form in triplicate. The base level quantity of formulation containing CLEVI used for spiking was $2500 \mathrm{ng} / \mathrm{band}$. The \%RSD and mean recovery were calculated.

\section{Precision}

The precision of proposed analytical method was done by repeatability (intra-day) and intermediate (inter-day) precision studies. The samples were analyzed three times on the same day (intra-day) and on three different days (inter-day precision). The $\%$ RSD value was calculated to determine intra-day and inter-day precision.

\section{Method sensitivity (Limit of detection and limit of quantification)}

The LOD and LOQ of the method were developed using regression equation. A series of standard preparation containing 1000-6000 ng/band were prepared over different levels. Calibration graphs were plotted for the obtained area under curve of each level against the concentration. The LOD and LOQ were calculated using equations $\mathrm{LOD}=3.3 \mathrm{x} \sigma / \mathrm{S}, \mathrm{LOQ}=10 \mathrm{x} \sigma / \mathrm{S}$, where $\sigma$ is the standard deviation of $y$-intercept and $S$ is the slope of calibration curve.

\section{Specificity}

Specificity is the ability of method to measure analyte in presence of its degradation products. Analytes were subjected to various stress conditions namely hydrolytic, oxidative, thermal and photolytic. Degraded samples were applied to the TLC plates and developed as mentioned previously. Developed densitograms were observed for resolution of degraded products.

\section{Robustness}

Robustness of analytical method is its capacity to remain unaffected by small but deliberate variation in method parameters. The HPTLC method parameters like saturation time of mobile phase, composition of mobile phase, time from spotting to development (solvent front). One factor at a time was changed and effect of $\mathrm{R}_{\mathrm{f}}$ and peak area of the drug (3000 ng/band) were studied. The \%RSD was calculated. 


\section{RESULTS}

\section{Development and optimization}

For selection of appropriate mobile phase for the development of CLEVI, trials were made by using solvents of different polarity, at different concentration levels. Several different composition of mobile phase system like water: methanol, methanol: acetonitrile, toluene: ethyl acetate were tried. Out the these, mobile phase toluene: ethyl acetate in a ratio of 8:2 was found to give sharp well defined peak at $R_{f}$ value of $0.49 \pm 0.0057$ for CLEVI which is shown in fig. 2. Densitogram with sharp defined peaks was obtained without any interference from analytes or excipients.

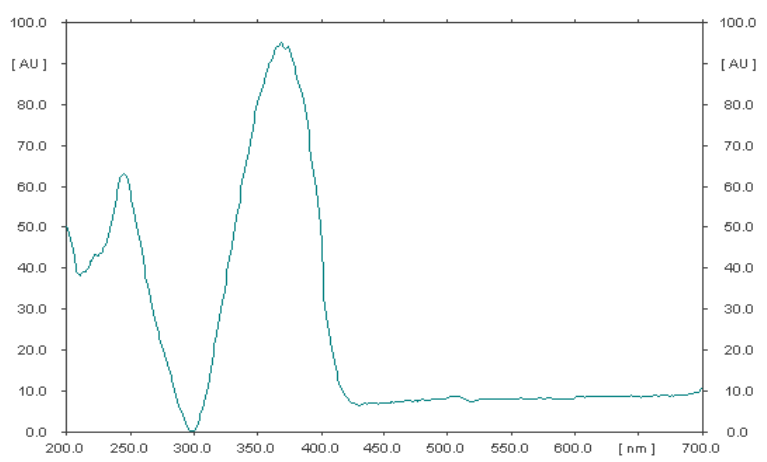

Fig. 1: UV spectra of CLEVI

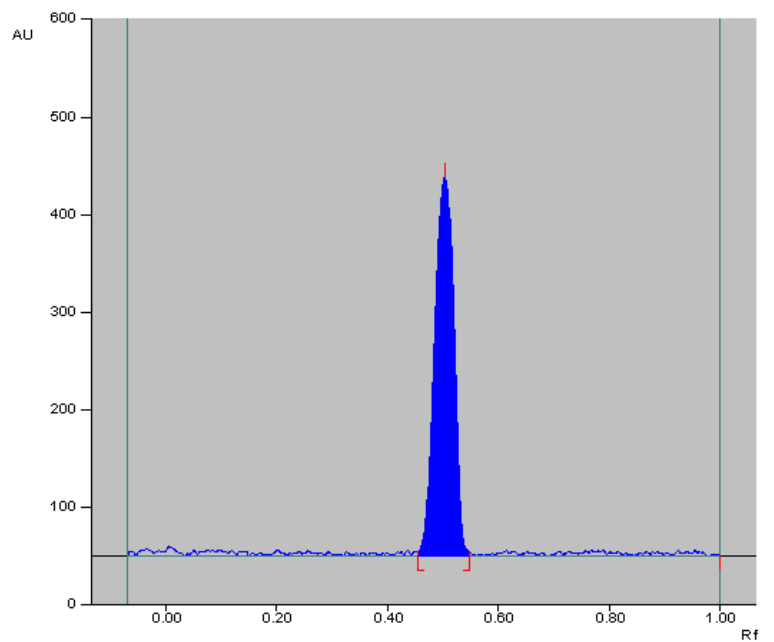

Fig. 2: Optimised densitogram of CLEVI

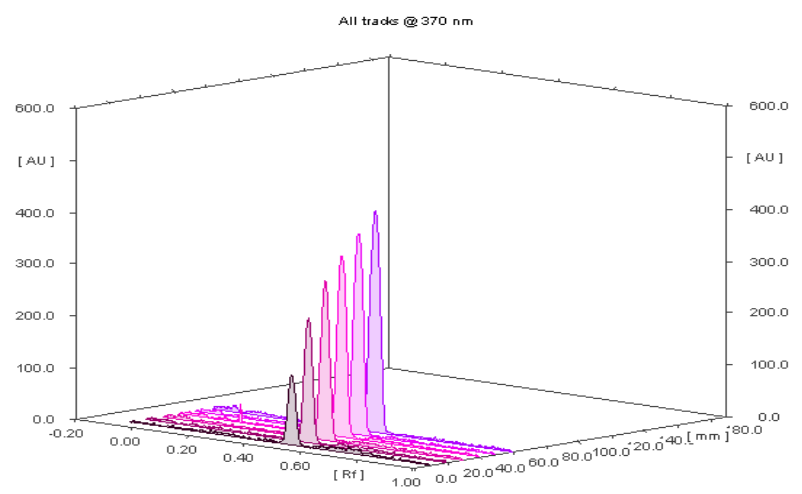

Fig. 3: Representative 3 D densitogram of linearity band of CLEVI

\section{Force degradation studies}

The results of force degradation study are summarized in table 1 . During stress degradation experiments it was observed that CLEVI was more susceptible to alkaline and acidic hydrolysis than oxidative, thermal and photolytic degradation.

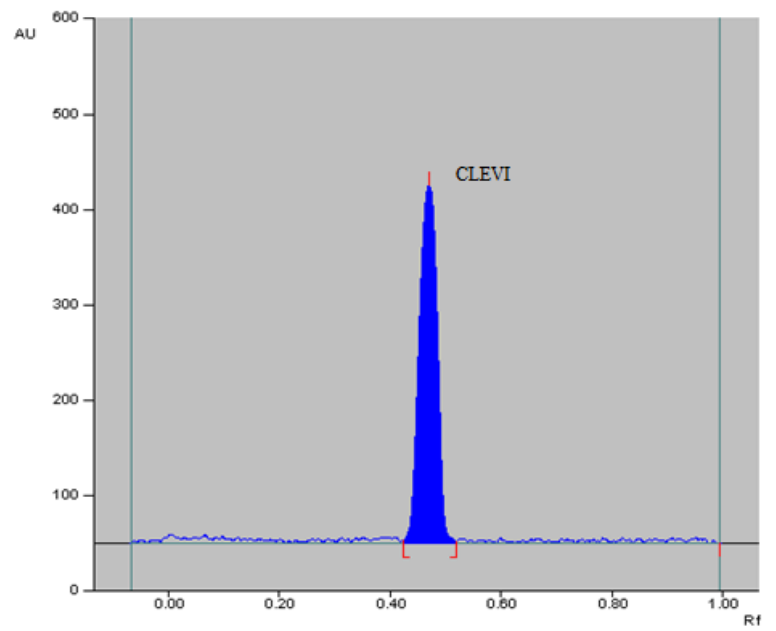

Fig. 4: Representative densitogram of CLEVI standard

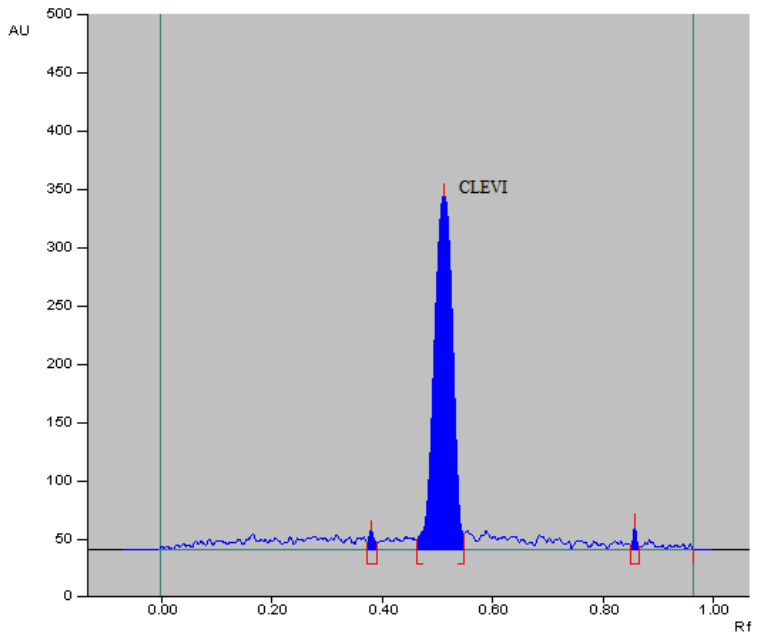

Fig. 5: Representative densitogram of CLEVI synthetic mixture

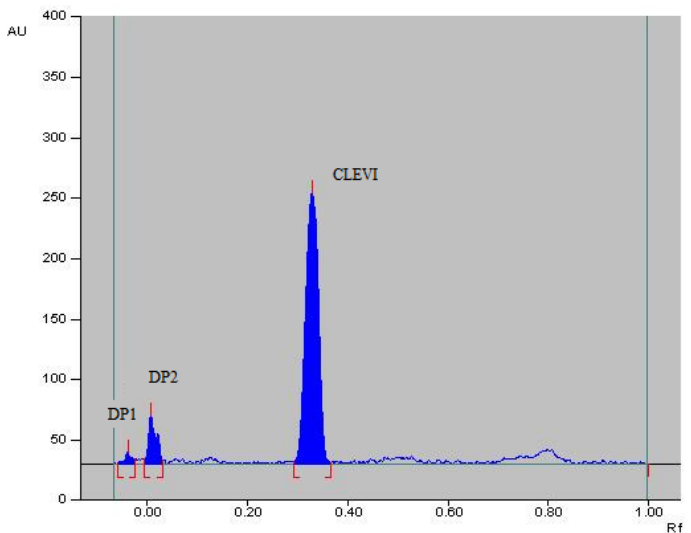

Fig. 6: Representative densitogram of $1 \mathrm{~N} \mathrm{HCl}$ at $60^{\circ} \mathrm{C}$ for $1 \mathrm{~h}$ 


\section{Validation of developed stability indicating method}

The developed method was validated as per ICH guidelines for parameters like linearity, accuracy, specificity, sensitivity and robustness. The $3 \mathrm{D}$ densitograms showed well resolved peaks. The linearity was evaluated by regression analysis. The linearity of densitograms is shown in Fig.3. The correlation coefficient was found to be greater than 0.999. The low values of LOD and LOQ indicate that developed method is sensitive to be used as stability indicating (table 2). Satisfactory \% recovery studies and lower \% RSD obtained in accuracy, precision, robustness (table 3, 4).

Thus this indicated the proposed method is robust to minor changes in the experimental conditions in the experimental conditions and can give accurate and precise results without any interference from injectable emulsion for the analysis of drug in the formulation.

Table 2: Forced degradation study of CLEVI

\begin{tabular}{|c|c|c|c|c|}
\hline & \multicolumn{2}{|l|}{ CLEVI (API) } & \multicolumn{2}{|c|}{ CLEVI (synthetic mixture) } \\
\hline Stress condition & $\mathrm{R}_{\mathrm{f}}$ of degraded product & $\%$ Degradation & $\mathrm{R}_{\mathrm{f}}$ of degraded product & \% Degradation \\
\hline $1 \mathrm{~N} \mathrm{HCl} 60^{\circ} \mathrm{C}$ for $1 \mathrm{hr}$ & $0.01,0.02$ & $22.5 \%$ & $0.01 ., 0.02$ & $19.5 \%$ \\
\hline $0.01 \mathrm{~N} \mathrm{NaOH} 60^{\circ} \mathrm{C}$ for $1 \mathrm{~h}$ & 0.27 & $45 \%$ & 0.27 & $41 \%$ \\
\hline $3 \% \mathrm{H}_{2} \mathrm{O}_{2} \mathrm{RT}$ for 1 hour & 0.27 & $8.5 \%$ & 0.27 & $6.3 \%$ \\
\hline Thermal $80^{\circ} \mathrm{C}$ for $8 \mathrm{~d}$ & -- & No degradation & ---- & No degradation \\
\hline Photolytic & 0.01 & $0.6 \%$ & 0.01 & $0.4 \%$ \\
\hline
\end{tabular}

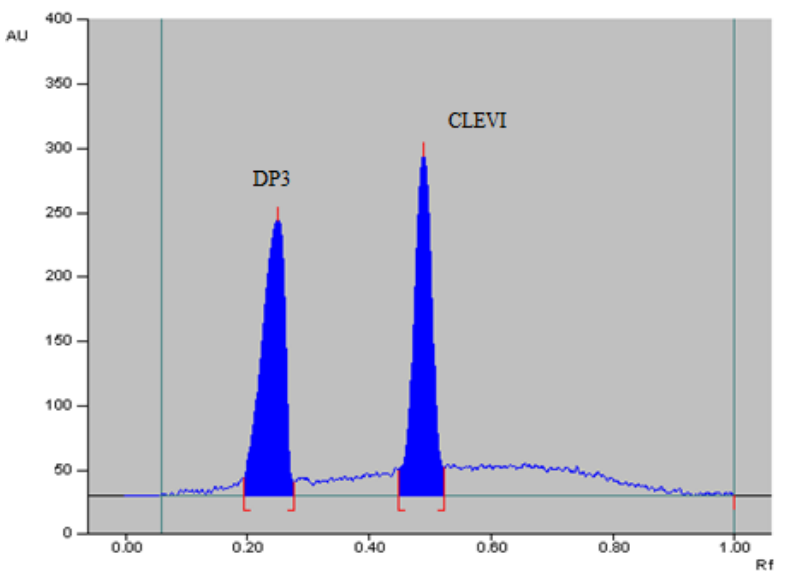

Fig. 7: Representative densitogram of $0.01 \mathrm{~N} \mathrm{NaOH}$ at $60^{\circ} \mathrm{C}$ for $1 \mathrm{~h}$

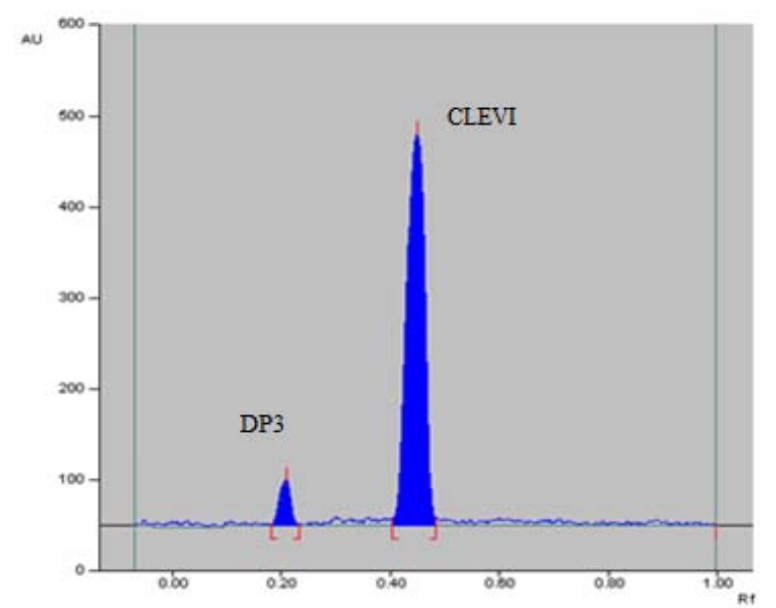

Fig. 8: Representative densitogram of $3 \% \mathrm{H} 2 \mathrm{O} 2$ at RT for $1 \mathrm{~h}$

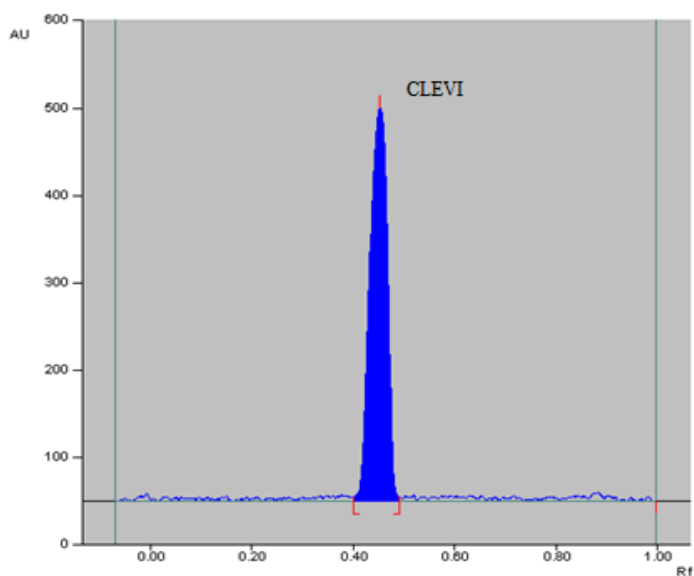

Fig. 9: Representative densitogram in Thermal at $80^{\circ} \mathrm{C}$ for $8 \mathrm{~d}$

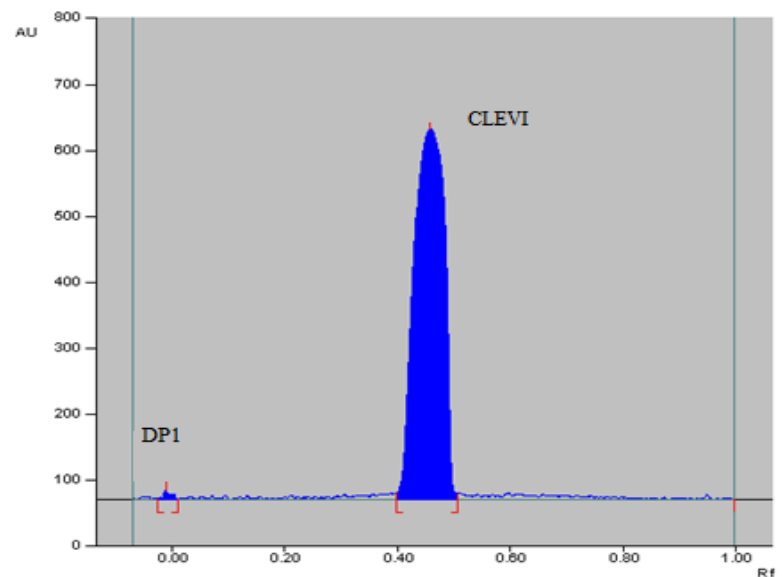

Fig. 10: Representative densitogram in Photolytic condition for $11 \mathrm{~d}$

Table 3: Result of linearity, range, precision, method sensitivity study

\begin{tabular}{ll}
\hline Parameter & CLEVI \\
\hline Concentration range (ng/band) & $1000-6000$ \\
Retention factor & $0.493 \pm 0.005$ \\
Regression equation & Y=1.877x+2410 \\
Correlation coefficient (R ${ }^{2}$ ) & 0.999 \\
Precision & 1.33 \\
Inter-day (\% RSD) & 1.16 \\
Intra-day (\%RSD) & \\
Method sensitivity & 403.22 \\
LOD(ng/band) & 1222.492 \\
LOQ(ng/band) & \\
\hline
\end{tabular}


Table 4: Results of accuracy (recovery) study by standard addition method ( $n=3)$

\begin{tabular}{cllllcr}
\hline $\begin{array}{c}\text { Concentration } \\
\text { (ng/band) }\end{array}$ & $\begin{array}{c}\text { \%Spiking } \\
\text { amount of } \\
\text { CLEVI added }\end{array}$ & $\begin{array}{c}\text { Amount of } \\
\text { CLEVI } \\
\text { recovered }\end{array}$ & mean \pm SD & \% RSD & \% Recovery & mean \pm SD \\
\hline 2500 & 1250 & 1237.6 & $1237.8 \pm 1.71$ & 0.142 & 99.02 & $99.03 \pm 0.14$ \\
2500 & 2500 & 2488.2 & $2488.6 \pm 1.59$ & 0.069 & 99.5 & 99.14 \\
2500 & 3750 & 3732.5 & $3733.96 \pm 1.55$ & 0.041 & 99.57 & $99.067 \pm 0.04$ \\
\hline
\end{tabular}

$\mathrm{n}=$ number of determinations, $\mathrm{SD}=$ Standard Deviation, $\% \mathrm{RSD}=\%$ Relative Standard Deviation

Table 5: Robustness study for the developed method $(n=3)$

\begin{tabular}{lllll}
\hline Condition & Parameter & $\mathbf{R}_{\mathbf{f}}$ (Mean) \pm SD & \% RSD & Area (mean \pm SD) \\
\hline Mobile phase composition & $7.8: 2.2$ & $0.47 \pm 0.005$ & 1.21 & $8085.6 \pm 111.18$ \\
& $8.2: 1.8$ & $0.52 \pm 0.005$ & 1.10 & $8023.26 \pm 75.9$ \\
Saturation of mobile phase & $17 \mathrm{~min}$ & $0.48 \pm 0.005$ & 1.19 & $8052.46 \pm 99.1$ \\
& $23 \mathrm{~min}$ & $0.49 \pm 0.005$ & 1.17 & $7911.83 \pm 65.74$ \\
Solvent front & $7.5 \mathrm{~cm}$ & $0.46 \pm 0.005$ & 1.23 & $8054.96 \pm 101.24$ \\
Wavelength & $8.5 \mathrm{~cm}$ & $0.52 \pm 0.005$ & 1.10 & $7939.53 \pm 106.37$ \\
& 368 & $0.48 \pm 0.005$ & 1.19 & $8075.25 \pm 61.42$ \\
& 372 & $0.49 \pm 0.005$ & 1.07 & $8022.33 \pm 62.98$ \\
\hline
\end{tabular}

$\mathrm{n}=$ number of determinations, $\mathrm{SD}=$ Standard Deviation, \%RSD $=\%$ Relative Standard Deviation

\section{DISCUSSION}

Force degradation studies play an important role in the development of pharmaceuticals. The results of degradation studies helps in development of stability indicating method. The ICH Q1A guideline states that the validated stability indicating test methods must be performed to monitor the shelf life of drug substance which are susceptible to change during storage and which are likely to affect the quality, safety, efficacy of formulation. HPTLC method has an advantage over HPLC methods in the form that the reported HPLC methods [9], method is developed by gradient method which is timeconsuming and method $[10,11]$ is isocratic with longer retention time while in hptlc method standard and sample can be analysed simultaneously on same TLC plate. Short equilibrium time, low solvent consumption, low volume of sample requirement, no preliminary treatment like filtration and degassing, more number of samples can be applied on TLC plate, shorter run time and less expensive are advantages of developed HPTLC method over reported HPLC method. From the development and validation studies it was found that the proposed method can resolve drug substances and degradation products in shorter time with optimum resolution.

\section{CONCLUSION}

The HPTLC method was developed on pre-coated silica gel using toluene: ethyl acetate $(8: 2)$ as mobile phase with densitometric detection at $370 \mathrm{~nm}$. This study found that HPTLC method development for determination of CLEVI in synthetic mixture is accurate, precise, linear, highly sensitive, specific and robust. The developed method was found to be suitable for determination of CLEVI in bulk and synthetic mixture.

\section{ACKNOWLEDGEMENT}

The authors are thankful to Anand Pharmacy College, Anand for providing facilities to carry out HPTLC work.

\section{AUTHORS CONTRIBUTIONS}

All authors have contributed equally to this manuscript.

\section{CONFLICT OF INTEREST}

None

\section{REFERENCES}

1. Deeks ED, Keating GM, Kem SJ. Clevidipine: a review of its use in the management of acute hypertension. Am J Cardiovas Drugs 2009;9 Suppl 2:117-34.

2. http://cleviprex.com [Last accessed on 20 Feb 2018]
3. Zhang H. Clevidipine (the Medicines Company). Curr Opin Investing Drugs 2002;3 Suppl 10:1474-8.

4. Zhou Y, Zou Q, Sun L, Wei P, Ouyang P. Determination of clevidipine and its primary metabolite in rat plasma by a dispersive liquid liquid micro extraction method. J Chromatograp Sci 2016;53:830-5.

5. Zhou Y, Li H, He X, Jia M, Ni Y. Simultaneous determination of clevidipine and its primary metabolite in dog plasma by liquid chromatography-tandem mass spectrometry: application to pharmacokinetic study. J Pharm Biomed Anal 2014;100:294-9.

6. Cao P, Li G, Huang L, Zhao S, Hu Y. Screening of stabilizers for LC-MS/MS analysis of clevidipine and its primary metabolite in dog whole blood. Bioanalysis 2015;7 Suppl 12:208-12.

7. Chen T, Zhang S, Ye P, Zhang F, Ni Y. Simultaneous determination of clevidipine and its primary metabolite in beagle plasma using LC-MS/MS. Chin J Clin Pharmaco Ther 2016;3:306-12.

8. Gyllenhaal 0. Fast enantioselective separation of clevidipine and dihydropyridine substituted acid by SFC on chiralpak AD. Fres J Anal Chem 2001;1 Suppl 369:54-6.

9. Zhou F, Yan F, Yang F, You Y. Structural analysis and quantitative determination of clevidipine butrate impurities using an advance RP-HPLC method. J Chromatogr Sci 2016;54:353-60.

10. Ma HB, Li Z L, Zhao J. HPLC method for determining of related substances in Clevidipine butyrate fat emulsion injection. Chinese J New Drugs 2015;16:1890-6.

11. Yuang H, Deng Y, Yu X, Wu Y, Chen X. Pre-formulation study of clevidipine butyrate and determination of its related substances by HPLC. J Shenyang Pharma Univ 2014;5:369-74.

12. Huang L, Sun H, Yang B, Yang S. Spectral analysis and structural elucidation of clevidipine butryate. Chinese J Magn Res 2011;1:168-75.

13. Clevidipine emulsion formulation containing antimicrobial agents. Patent-US20120088804 A1.

14. Chauhan K, Mujawar A, Quazi I. HPTLC method development and validation for densitometric analysis of carbosteine in drug formulation. Int J Appl Pharm 2016;8 Suppl 2:22-6.

15. Syal P, Kumar R, Arora G. Simultaneous estimation of thiocolchicoside and aceclofenac by HPTLC. Int J Curr Pharma Res 2017;9 Suppl 4:55-60.

16. Nariya P, De S. Development and validation of a reverse phase planar chromatography method for determination of NHT and its application in food products. Asian J Pharm Clin Res 2013;6 Suppl 5:76-8.

17. Patil PM, Wankhede SB, Chaudhari PD. A validated stability indicating HPTLC method for estimation of acyclovir in presence of its alkaline degradation products. Bull Faculty Pharmacy Cairo University 2014;52:245-57. 
18. ICH. Validation of analytical procedures: Text and methodology Q2(R1), International Conference on Harmonization; 2005.
19. ICH. Stability testing of new drug substances and products Q1A(R2), International Conference on Harmonization; 2003. 